\title{
Investigation of Dynamics of Faradaic Processes in Polypyrrole Films by Electrochemical Impedance and Color Admittance Spectroscopies
}

\author{
Takashi AmEMIYA, Kazuhito HASHIMOTO and Akira FUJISHIMA*
}

Received June 26, 1992 ; Accepted August 17, 1992

\begin{abstract}
Dynamics of faradaic processes in polypyrrole ( $P P y$ ) films depending on the thickness of the films and on applied dc potentials have been investigated by ac electromodulation spectroscopy techniques. The comparison of the capacitance plots derived from the impedance plots with the modulated transmittance (color admittance, $\Delta \mathrm{T} / \Delta \mathrm{E}$ ) plots revealed whether the overall electrical responses were due to faradaic processes in the PPy films or not. The results showed that the faradaic processes in both the thicker $(0.26 \mu \mathrm{m})$ and the thinner $(c a .0 .03 \mu \mathrm{m})$ PPy films in their highly oxidized state were represented by a single relaxation process, and that those in the thicker films in their intermediately oxidized state were clearly resolved into two processes, the faster and the slower processes. The differences in mechanisms of the faradaic processes between the thicker and the thinner films depending on the dc potentials are discussed by using an electrical equivalent circuit.
\end{abstract}

\section{INTRODUCTION}

Electrodes coated with conducting polymer films are applied to electronics 1 ), batteries $^{2}$ and electrochromic devices ${ }^{3}$ ) because of their unique electrical and optical properties. In many of these applications, charge transport processes in the films play an important role to determine the kinetic properties. The kinetics of conducting polymers have been mainly investigated by pulse techniques ${ }^{4}$ and ac impedance techniques 5 ). In particular, the ac impedance technique has been shown to be a powerful method for the investigation of the kinetic processes in conducting polymers 5 ). Recently, in order to make clear the faradaic

Department of Synthetic Chemistry, Faculty of Engineering, The University of Tokyo, Bunkyo-ku, Tokyo 113, Japan

Key words: polypyrrole, impedance, color admittance contributions to the kinetics of conducting polymers, optical measurement has been combined with the ac impedance measurement ${ }^{6}$. The optical transmittance (T) of the films is perturbed by an ac electromodulation $(\Delta E)$, and the optical response $(\Delta T / \Delta E$, called color admittance hereinafter) is observed in the frequency domain. The advantage of this technique is that only faraclaic processes in the films can be separately monitored from the other electrochemical processes.

In the papers 7,8 ) of this series, the advantages of the color admittance technique in the application to polypyrrole (PPy) films have been demonstrated, and the results are briefly summarized as follows: (i) the electrical responses in a electrochemical system including PPy films in their highly or slightly oxidized state corresponded to the faradaic processes (color admittances) in the films, however, 
the responses did not correspond to the faradaic processes in the films when they were in their reduced state. (ii) In the presence of a redox couple in a solution, only faradaic processes in PPy films were separately monitored from the other electrochemical reactions due to the redox couple by employing the color admittance technique.

In this paper, differences in dynamics of faradaic processes in polypyrrole (PPy) films depending on the thickness of the films and on applied dc potentials are shown by the electrochernical impedance and the color admittance data. Analysis of the data shows that a mechanism for the faradaic processes in the thinner PPy films is completely different from that in the thicker films which is reported elsewhere in detail7).

\section{EXPERIMENTAL}

An electrochemical cell halving two optical windows (area, $0.78 \mathrm{~cm}^{2}$ ) was used in all of the studies. A glass coated with indium doped tin oxide (ITO) was fitted to one of the optical windows of the cell and was used as a working electrode. A saturated calomel electrode (SCE) and a platinum plate (area, $4.5 \mathrm{~cm}^{2}$ ) were used as a reference and a counter electrodes, respectively. Polypyrrole $\left(\mathrm{PPy} / \mathrm{Cl}^{-}\right)$films were prepared by oxidation of a saturated $\mathrm{KCl}$ (Tokyo Kasei Co.) aqueous solution containing $0.1 \mathrm{M}$ pyrrole at constant current of $1.3 \mathrm{~mA} / \mathrm{cm}^{2}$. The charges consumed in the polymerization were 78 $\mathrm{mC} / \mathrm{cm}^{2}$ and $9.1 \mathrm{mC} / \mathrm{cm}^{2}$ for thicker $(0.26 \pm 0.03 \mu \mathrm{m})$ and thinner $(c a .0 .03 \mu \mathrm{m})$ films, respectively. After the film deposition, the cell and films were washed with distilled water, and a fresh electrolyte (sat. $\mathrm{KCl}$ aq.) was introduced into the cell.

Electrochemical impedance and color admittance measurements were performed as follows after cyclic voltammetry. First, a conventional ac impedance measurement at a constant $\mathrm{dc}$ potential was carried out with a potentiostat (model 2020, Toho Technical Research) and a frequency response analyzer (F.R.A.) (model S5720B NF Circuit, Ltd.). Next, under the same conditions as the impedance measurement, transmittance of the PPy films was monitored at $700 \mathrm{~nm}$ from a tungsten lamp through a monochrometer. The transmitted light intensity was detected with a PIN photodiode and the photodiode output was fed via a wideband current amplifier (model LI-76, NF Circuit, Ltd.) to the F.R.A. After getting a set of the impedance and the color admittance data, the dc potential was changed to another value, and next set of the data were acquired by the same procedure described above. The experimental arrangement is schematically shown in Fig. 1. The data were represented in the complex planes in

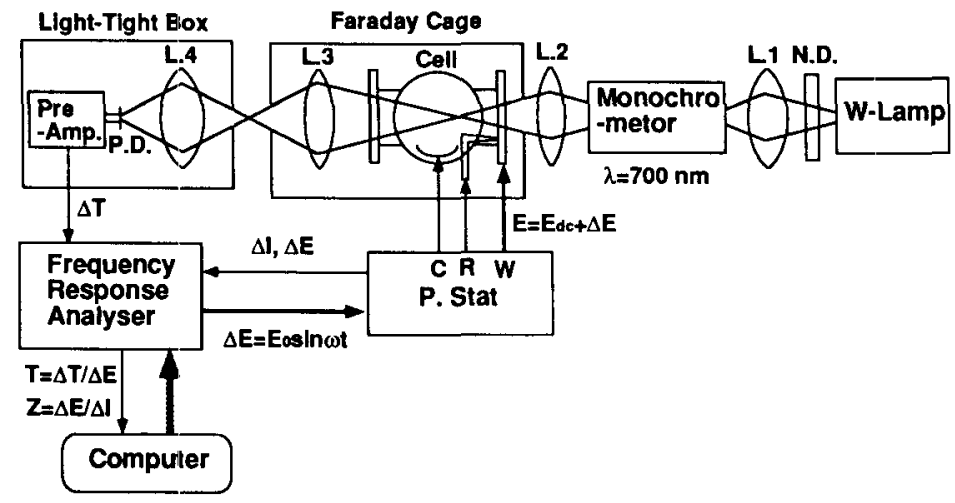

Fig. 1. Block diagram of the experimental setup for the electrochemical impedance and color admittance spectroscopies. 
the form of $Z(=\Delta E / \Delta I)$ or $C(=\Delta Q / \Delta E=1 / i \omega Z)$ for the electrical responses, and $T(=\Delta T / \Delta E)$ for the optical responses.

\section{RESULTS AND DISCUSSION}

\subsection{Cyclic voltammetry.}

Figure 2 shows typical cyclic voltammograms of both thicker $(0.26 \mu \mathrm{m})$ and thinner $(c a, 0.03 \mu \mathrm{m}) \mathrm{PPy} / \mathrm{Cl}^{-}$films. The voltammogram of the thinner film had one pair of redox peak around a formal potential $\mathrm{E}^{\prime}(-0.4 \mathrm{~V})$, and the anodic peak $(-0.35 \mathrm{~V})$ and the cathodic peak $(-0.45 \mathrm{~V})$ were nearly symmetrical about the $\mathrm{E}^{\circ}$. On the other hand, the peak separation of the voltammogram for the thicker film increased to $c a$. $400 \mathrm{mV}$, and the cathodic peak around $-0.6 \mathrm{~V}$ was equivocal. In addition, the redox peaks were not symmetrical. It is considered that the irreversibility of the redox reaction of the thicker PPy films is due to slow dopingundoping processes of counter ions and/or slow electron hopping in the films ${ }^{7,9}$ ). Thus the differences in the shapes of the voltammograms between the thicker and the thinner films as shown in Fig. 2 indicate that the slow charge (electron and/or ion) transport processes become

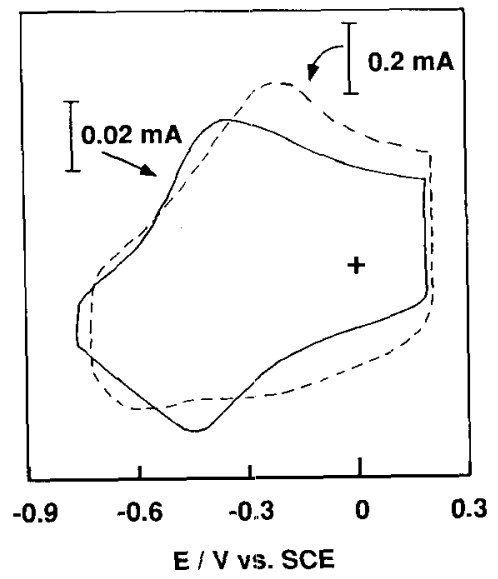

Fig. 2. Cyclic voltammograms of a thicker $(0.26 \mu \mathrm{m})$ and a thinner $(c a .0 .03 \mu \mathrm{m})$ PPy/C1- films in saturated $\mathrm{KCl}$ aqueous solution. Electrode area was $0.78 \mathrm{~cm}^{2}$, and scan speed was $50 \mathrm{mV} / \mathrm{s}$. The dashed line (-.-) and the full line (- ${ }^{-}$) are for the thicker and the thinner films, respectively. more dominant with increasing the thickness of the films.

\subsection{Impedance plots for the thicker and thinner films.}

Figure 3 shows impedance $(Z)$ plots of both the thicker and the thinner films at $0.2 \mathrm{~V}$ and $-0.3 \mathrm{~V}$. One of the noticeable features in the $Z$ plots is that the straight (a) $0.2 \mathrm{~V}$

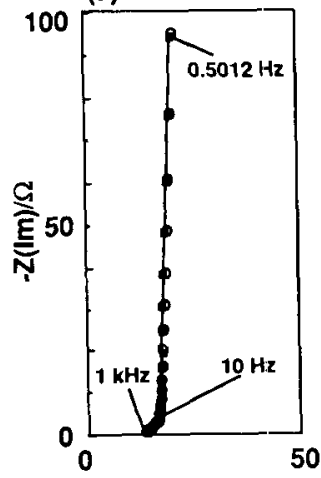

50

$\mathrm{Z}(\mathrm{Re}) / \Omega$

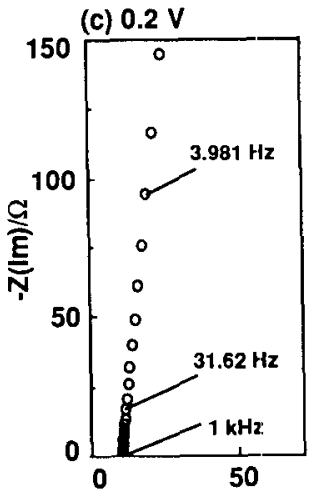

(b) $-0.3 \mathrm{~V}$

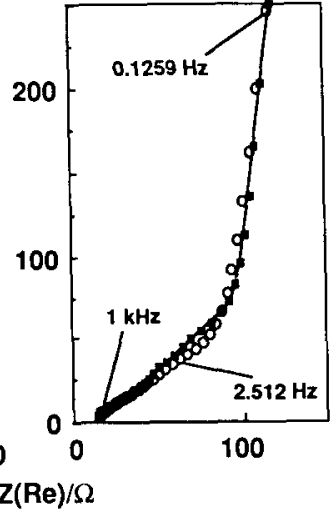

(d) $-0.3 \mathrm{~V}$

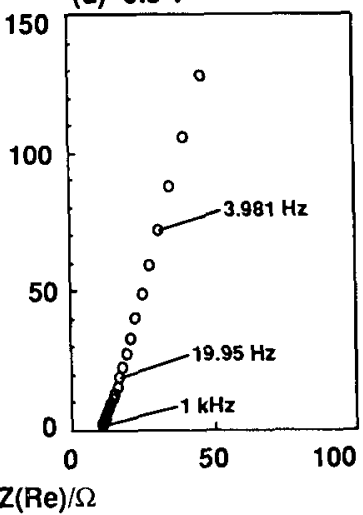

Fig. 3. Complex impedance plots for a thicker ((a) and (b)) and a thinner ((c) and (d)) $\mathrm{PPy} / \mathrm{Cl}^{-}$films in saturated $\mathrm{KCl}$ aqueous solution at $0.2 \mathrm{~V}$ and at $-0.3 \mathrm{~V}$. Points $(\mathrm{O})$ show experimental data and smooth curves (--) for the thicker film show simulation by the equivalent circuit as shown in Fig. 5. The simulation was performed with the following parameters: (a) $\tau_{1}=0.04 \mathrm{~s}, \mathrm{C}_{\mathrm{T} 1}=3.2 \mathrm{mF}, \tau_{2}=1 \mathrm{~s}, \mathrm{C}_{\mathrm{T} 2}=0.3 \mathrm{mF}$, $R_{\Omega}=13 \Omega, R_{c t}=0 \Omega$ and $C_{d}=0 F$. (b) $\tau_{1}=1.2 \mathrm{~s}$, $\mathrm{C}_{\mathrm{T} 1}=4.3 \mathrm{mF}, \tau_{2}=460 \mathrm{~s}, \mathrm{C}_{\mathrm{T} 2}=8 \mathrm{mF}, \mathrm{R}_{\Omega}=13 \Omega$, $R_{c t}=10 \Omega$, and $C_{d}=50 \mu F$. (see text) 
lines with a slope of $c a .45^{\circ}$ (referred to as a Warburg impedance ${ }^{10}$ ) ) were observed for the thicker films, however the Warburg impedance never appeared for the thinner films at any potentials $(0.2 \mathrm{~V}$, $0 \mathrm{~V}, \quad-0.15 \mathrm{~V}, \quad-0.3 \mathrm{~V}$ and $-0.5 \mathrm{~V}$ ) investigated here. The Warburg impedance represents semi-infinite diffusion of chemical species in the films11). The finite thickness of the films causes the phase angle to shift from $45^{\circ}$ in the diffusion controlled region to $90^{\circ}$ in the charge saturation region. In the case of the thinner films, the reason why the Warburg impedance was not observed at any potentials is considered as follows: the frequency region in which the electrical response is controlled by charge transfer at the electrode/film and/or at the film/solution interfaces may overlap with the charge saturation region, and no diffusion controlled region will be observed11,12). Though the electrical responses between the thicker and the thinner PPy films were different from one another as shown in Fig. 3, they will be proved to be the faradaic processes in the PPy films below.

\subsection{Capacitance plots and color admittance plots.}

Figure 4 shows the capacitance (C) and the color admittance (T) plots for the $\mathrm{PPy} / \mathrm{Cl}^{-}$ films measured under the same conditions as shown in Fig. 3. The $\mathrm{C}$ plots were obtained from the $\mathrm{Z}$ plots as $\mathrm{C}=(1 / \mathrm{Z})(1 / \mathrm{i} \omega)$. This form of presentation turned out to be advantageous to see very slow charging processes at low frequency. The shapes of the $\mathrm{C}$ plots and the $\mathrm{T}$ plots for both the thicker and the thinner films at $0.2 \mathrm{~V}$ were nearly identical with each other, and comprised single semicircles. The coincidence between the $T$ plots with the $C$ plots indicates that the chargingdischarging processes are faradaic in the films. In addition, these semicircles represent that the faradaic processes in the films at $0.2 \mathrm{~V}$ consist of one relaxation process characterized by the top frequency $\left(f_{t \circ p}\right)$. The relaxation time $\left(\tau=1 /\left(2 \pi f_{t o p}\right)=5.0 \mathrm{~ms}\right)$ for the thinner film is over one order of magnitude smaller than that $(63 \mathrm{~ms})$ for the thicker film. The difference in the relaxation time between the thinner and the thicker films probably arises from the difference in the film capacitances. The $\mathrm{PPy} / \mathrm{Cl}^{-}$films behave like pure capacitors in their highly conducting state (at $0.2 \mathrm{~V}$ ). Therefore, the response time is controlled by the $\mathrm{RC}$ time constants associated with the series combination of the electrolyte resistance $(13 \Omega)$ and the film capacitances $(0.4 \mathrm{mF}$ for the thinner films and $3.2 \mathrm{mF}$ for the thicker films).

The faradaic processes in both the thicker and the thinner films at $-0.3 \mathrm{~V}$ were more complicated than those at $0.2 \mathrm{~V}$, and were not represented by a single relaxation process. In the case of the thicker film, the faradaic processes were clearly resolved into two processes (the faster and the slower processes), though the resolution of the two faradaic processes was equivocal for the thinner film. The $T$ plots at low frequencies for the thinner films at $-0.3 \mathrm{~V}$ were scattered, and it is difficult to say that the electrochemical processes were dominantly faradaic in the films in this case. The response time for the thicker film at $-0.3 \mathrm{~V}$ is seemed to be controlled by two diffusion processes of $\mathrm{Cl}^{-}$ in the films. The faradaic processes in the thicker films will be simulated by using an electrical equivalent circuit having two Warburg type impedance elements.

\subsection{Equivalent circuit analysis.}

Figure 5 shows a modified Randles' equivalent circuit13) employed to reproduce the experimental data for the thicker film. The treatment of the two faradaic impedance branches in the equivalent circuit is similar to those reported elsewhere ${ }^{14}$ ). The mathematical form of both $Z_{1}$ and $Z_{2}$ is given as follows by using the finite length transmission line model 14,15)

$$
\mathrm{Z}_{\mathrm{j}}=\underset{j=1,2}{\left(\tau_{\mathrm{j}} / \mathrm{C}_{\mathrm{Tj}}\right) \operatorname{cotnh}\left[\left(\mathrm{i} \omega \tau_{\mathrm{j}}\right)^{1 / 2}\right] /(\mathrm{i} \omega \tau \mathrm{j})^{1 / 2}}
$$

where $\tau$ is the characteristic time constant of the line, $\omega$ is an angular frequency, $C_{T} j$ is the total distributed charge capacity of 
the line associated with the faradaic processes in the $\mathrm{PPy} / \mathrm{Cl}^{-}$films. The simulated curves for the thicker films are depicted in Figs. 3 and 4 . The unknown parameters for the simulation were three $\left(\tau_{1}, \tau_{2}\right.$ and $\left.\mathrm{C}_{\mathrm{T} 2}\right)$ at $0.2 \mathrm{~V}$, and five $\left(\tau_{1}, \tau_{2}, \mathrm{C}_{\mathrm{T} 2}\right.$, $R_{c t}$ and $C_{d}$ ) at $-0.3 \mathrm{~V}$. Other parameters were obtained experimentally. Both the $\mathrm{Z}$ and the $C$ plots were effectively used to determine the parameters. The simulated $T$ plots were obtained from the $C$ plots by assuming Faraday's law

$$
(\Delta \mathrm{T} / \Delta \mathrm{E})=\mathrm{K}(\Delta \mathrm{Q} / \Delta \mathrm{E})
$$

where $\mathrm{K}$ is a constant. The fit of the data using the equivalent circuit is very good, indicating that the faradaic processes in the thicker $\mathrm{PPy} / \mathrm{Cl}^{-}$films consist of two parallel processes, the faster and the slower processes. In the previous paper, we discussed in detail the mechanism for
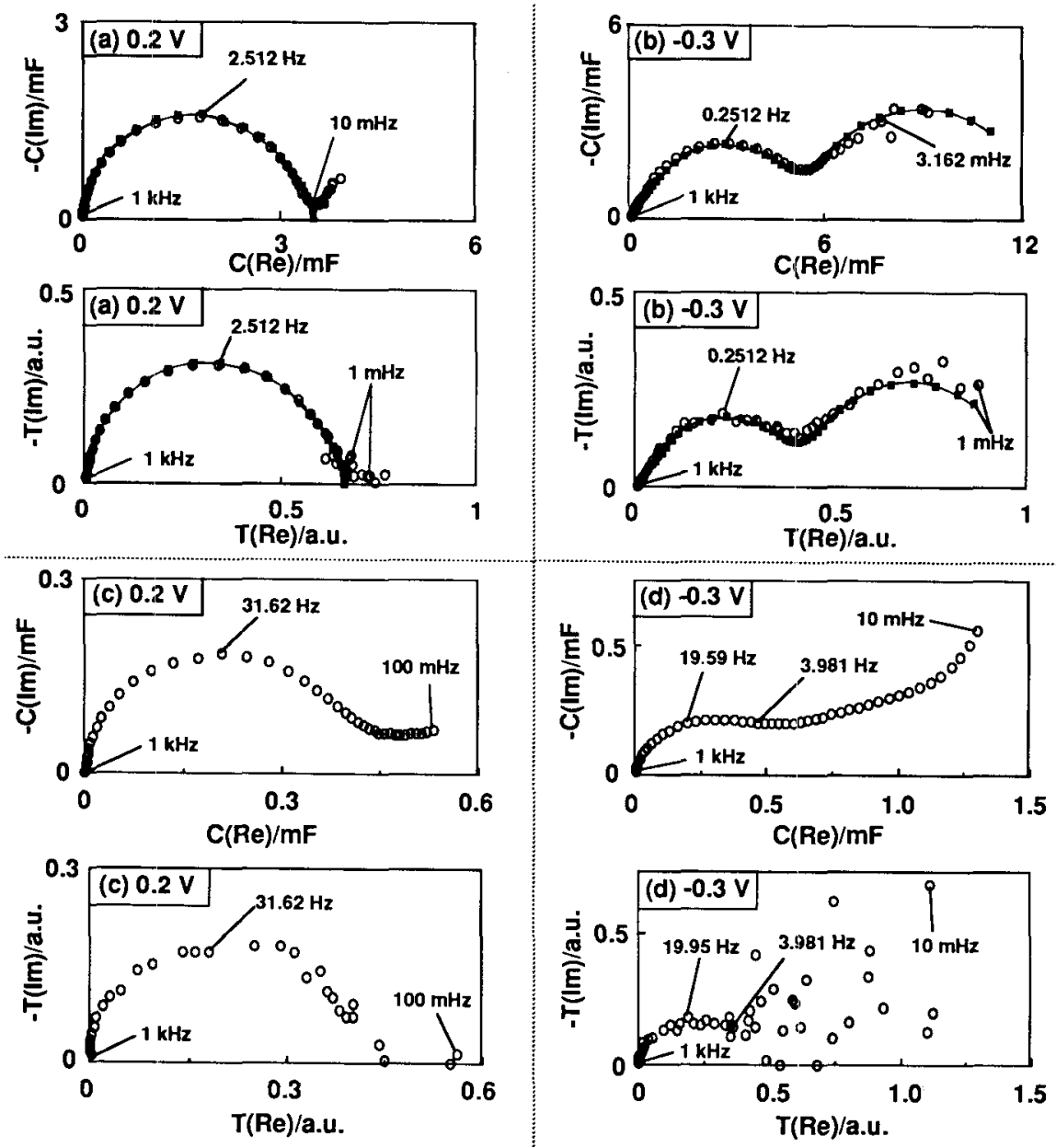

Fig. 4. Complex capacitance (C) and complex color admittance (T) plots at $700 \mathrm{~nm}$ for a thicker ((a) and (b)) and a thinner ((c) and (d)) $\mathrm{PPy} / \mathrm{Cl}^{-}$ films under the same conditions as shown in Fig. 3 . The fitting parameters used for the simulation are the same values as shown in Fig. 3. The $T$ plots for the thicker film were reproduced by assuming $T=K C$. Where $K$ is constant. 


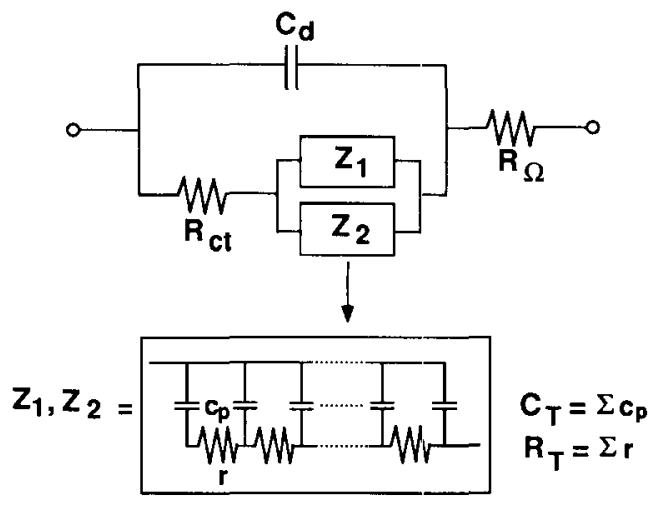

Fig. 5. Electrical equivalent circuit used to obtain the simulated plots for a thicker $\mathrm{PPy} / \mathrm{Cl}-$ film as shown in Figs. 3 and $4 . \mathrm{R}_{\Omega}$ is solution plus ITO resistance, $R_{c t}$ is charge transfer resistance and $C_{d}$ is double layer capacity at ITO/film interface. $Z_{1}$ and $Z_{2}$ respectively represent the impedance corresponding to the faster and the slower faradaic processes in the film.

the faster and the slower faradaic processes in the thicker PPy films ${ }^{7)}$.

In the case of the thinner films, however, we could not fit the data by using the equivalent circuit as shown in Fig. 5 or a typical Randles'-type equivalent circuit modified for thin films ${ }^{11}$ ). The dependence of the kinetics of PPy films on the film thickness has been investigated for relatively thicker films $\left.(>1 \mu \mathrm{m})^{16}\right)$. It is reported in the literature that the counter ion diffusion in the PPy films becomes faster as the thickness decreases 16). However, for very thin films $(<0.03 \mu \mathrm{m})$ as used in this study, both the diffusion processes at high frequency and slower faradaic processes at low frequency were not clearly observed. This means that the time constant $\tau_{1}$ for the thinner film is much smaller than that $(0.04 \mathrm{~s})$ for the thicker film and that the slower faradaic processes in the thinner film are absent or are not represented by the finite length transmission line $\left(Z_{2}\right)$ as shown in Fig. 5 . In addition, analysis of data for the very thin films using an electrical equivalent circuit has not, to our knowledge, been reported. Thus it is concluded that not only the counter ion diffusion is very fast in the very thin films but also a mechanism for the faradaic processes in the very thin films is probably different from that in the thicker films.

\section{REFERENCES}

1) (a) H. S. White, G. P. Kittlesen and M. S. Wrighton, J. Am. Chem. Soc., 106, 5375 (1984). (b) J. W. Thacheray, H. S. White and M. S. Wrighton, J. Phys. Chem., 89, 5133 (1985). (c) A. Tsumura, H. Koezuka and T. Ando, Appl. Phys. Lett., 49, 1210 (1986).

2) (a) N. Mermilliod, J. Tanguy and F. Petiot, J. Electrochem. Soc., 133, 1073 (1986). (b) R. J. Mammone and M. Binder, J. Electrochem. Soc., 137, 2135 (1990).

3) (a) J. C. Lacroix, K. K. Kanazawa and A. Diaz, J. Electrochem. Soc., 136, 1308 (1989). (b) T. Amemiya, K. Itoh and A. Fujishima, Ber. Bunsenges. Phys. Chem. 93, 682 (1989). (c) T. Amemiya, K. Hashimoto, K. Itoh and A. Fujishima, $J$. Electrochem. Soc., 138, 2845 (1991).

4) (a) P. G. Pickup and R. A. Osteryoung, $J$. Electroanal. Chem., 195, 271 (1985).

(b) P. Marque, J. Roncali and F. Garnier, J. Electroanal. Chem., 218, 107 (1987).

(c) C. D. Paulse and P. G. Pickup, J. Phys. Chem., 92, 7002 (1988).

5) (a) S. H. Glarum and J. H. Marshall, $J$. Electrochem. Soc., 134, 142 (1987). (b) I. Rubinstein, E. Sabatani and J. Rishpon, J. Electrochem. Soc., 134, 3078 (1987). (c) R. M. Penner and C. R. Martin, J. Phys. Chem., 93, 984 (1989). (d) C. M. Elliott, A. B. Kopelove, W. J. Albery and Z. Chen, J. Phys. Chem., 95, 1743 (1991).

6) (a) R. S. Hutton, M. Kalaji and L. M. Peter, J. Electroanal. Chem., 270, 429 (1989). (b) R. Greef, M. Kalaji and L. M. Peter, Faraday Discuss. Chem. Soc., 88, 277 (1989). (c) C. Gabrielli, M. Keddam and $\mathrm{H}$. Takenouti, Electrochim. Acta., 35, 1553 (1990).

7) T. Amemiya, K. Hashimoto and A. Fujishima, submitted to J. Phys. Chem.

8) T. Amemiya, K. Hashimoto and A. Fujishima, submitted to J. Phys. Chem.

9) J. Tanguy, N. Mermilliod and M. Hoclet, 
J. Electrochem. Soc., 134, 795 (1987).

10) A. J. Bard and L. R. Faulkner, Electrochemical Methods., John Wiley \& Sons. New York, Chapter 9 (1980).

11) (a) C. Ho, I. D. Raistrick and R. A. Huggins, J. Electrochem. Soc., 127, 343 (1980). (b) D. R. Franceschetti and J. R. Macdonald, J. Electrochem. Soc., 129, 1754 (1982).

12) T. B. Hunter, P. S. Tyler, W. H. Smyrl and H. S. White, J. Electrochem. Soc., 134, 2198 (1987).
13) J. E. B. Randles, Disc. Faraday Soc., 1, 11 (1947).

14) (a) J. Rishpon and S. Gottesfeld, $J$. Electrochem. Soc., 131, 1960 (1984). (b) I. Rubinstein, J. Rishpon and S. Gottesfeld, J. Elctrochem. Soc., 133, 729 (1986).

15) I. D. Raistrick, Electrochim. Acta, 35, 1579 (1990).

16) T. Osaka, K. Naoi, S. Ogano and S. Nakamura, J. Electrochem. Soc., 134, 2096 (1987). 